\title{
LA PRODUCCIÓN DE ORACIONES RELATIVAS EN NIÑOS MEXICANOS DE SEIS AÑOS
}

Una de las estructuras sintácticas privilegiadas en los estudios sobre la adquisición del lenguaje infantil es sin duda la de la oración relativa. Son frecuentes los estudios en torno a esta estructu$\mathrm{ra}$, con no menos frecuentes alusiones a la dificultad que ofrece al niño en todas las dimensiones de su competencia lingüística. Baste con algunos ejemplos:

Relative clauses are a particularly difficult construction for children to produce (Menyuc 1969...), comprenhend (Gaer 1969, H.D. Brown $1971 \ldots$ ), and imitate (C. Smith 1970, Slobin...)1.

Most speakers of a language share the intuition that some structures are more complicated than others... Sentences with relative clauses are more complicated than sentence without ${ }^{2}$.

La relative est traditionnellemente considérée comme une structure particulierement complexe ${ }^{3}$.

De lo anterior se desprende que existe un evidente nexo entre complejidad y estructura relativa, aunque no se explicite el porqué de esta complejidad. Precisamente del interés por este nexo y de su relación con el proceso de adquisición de la sintaxis surgió este trabajo.

${ }^{1} \mathrm{~S}$. TAVAKolian, "The conjoined clause. Analysis of relative clauses", en Language acquisition and linguistic theory, MIT Press, Cambridge, 1981, p. 168.

${ }^{2}$ H. Clark y E. Clark, Psychology and language. An introduction to psycholinguistics, Harcourt Brace Jovanovich, New York, 1977, p. 337.

${ }^{3}$ C. Hudelot, 'Qu'est-ce que la complexité syntaxique? L'example de la relative", LingP, 1980, núm. 2, p. 16. 
Partiendo de la base de que el concepto de complejidad lingüística - pese a ser uno de los más ricos y productivos para dar cuanta de la naturaleza del lenguaje ${ }^{4}-$ no es un término que pueda definirse en sí mismo, sino siempre en relación con un hecho dado, se decidió tomar la "jerarquía de accesibilidad de relativización", propuesta por Edward Keenan y Bernard Comrie ${ }^{5}$, como punto de apoyo para el análisis de las oraciones relativas producidas por niños mexicanos. Esta jerarquía, resultado de un estudio tipológico, permite relacionar la complejidad con un hecho concreto: posiciones de relativización, entendidas como las diversas funciones sintácticas que puede desempeñar el nexo relativo dentro de la oración subordinada.

Si bien es cierto que Keenan y Comrie no explican el porqué de la dificultad de la relativa, también es cierto que la jerarquía, como tal, supone un grado de complejidad relacionado con el lugar relativizado, y es esta gradación la que permite hacer algunas interpretaciones acerca de la adquisición de esta estructura.

\section{EL CORPUS}

El experimento "Plática libre" del proyecto Estudio Sociolingüístico de Lenguaje Infantil, que se desarrolla en el Centro de Estudios Lingüísticos y Literarios de El Colegio de México ${ }^{6}$, sirvió para seleccionar el corpus de oraciones relativas especificativas analizadas en este trabajo. Este experimento se aplicó a una muestra de sesenta y un niños de seis a siete años del Distrito Fe-

${ }^{4}$ En el campo de la adquisición, el concepto de complejidad ha sido medular en la investigación del desarrollo lingüístico del niño: "We can learn a good deal from discovering just what constitutes formal linguistic complexity for the child. If we can order linguistic devices in terms of their acquisition complexity, we can begin to understand the strategies used by the child in arriving at the grammar of his language $[. .$.$] a definition of what is simple for$ a child to acquire is a definition of the child's first guess as to the nature of language" (D. SLoBIN, "Cognitive prerequisites for the development of grammar", en Studies of child language development, eds. Ch. A. Ferguson y D. I. Slobin, Holt, Rinehart and Winston, MIT Press, Cambridge, 1981, p. 181.

${ }^{5}$ E. KeENAN y B. ComRIE, "Noun phrase accessibility and universal grammar", $L I, 8$ (1977), 63-99. Esta jerarquía fue establecida a raíz de un estudio tipológico sobre la oración relativa especificativa en 50 lenguas.

${ }^{6}$ Este proyecto, coordinado por Oralia Rodríguez, fue diseñado en 1982 , para hacer una descripción de la gramática oracional infantil, con base en las transcripciones de los experimentos grabados en el primer semestre de 1976 para el proyecto "Clase social, familia, lenguaje", entonces dirigido por Hans Saettele. 
deral, de tres diferentes grupos sociales: marginal, obrero y medio ${ }^{7}$.

El material lingüístico que hay en este estudio tiene varias ventajas. En primer lugar, permite manejar una gran cantidad de lengua oral producida por niños mexicanos; en este experimento no había un guión previo, ni un objetivo específico: la meta era que el niño hablara libremente - lo más posible dentro de la situación de experimento dada- alrededor de quince o veinte minutos.

En segundo lugar, la edad que tenían los niños de la muestra cuando se les aplicó el experimento (seis a siete años) es por demás interesante, pues está considerada como un momento en las llamadas etapas tardías de la adquisición. Durante mucho tiempo se afirmó en los estudios sobre adquisición de lenguaje infantil que el niño de seis años ya había adquirido la sintaxis de su lengua. Sin embargo, a raíz de nuevas investigaciones, se sabe que hay estructuras sintácticas que, o bien hacen su aparición tardíamente ${ }^{8}$, o bien presentan ciertas peculiaridades en su manejo, que comprueban que el dominio de la sintaxis en algunos niveles de la competencia infantil aún es endeble:

A common assumption among students of child languages has been that the child has mastered the syntax of his native language by about age $5[\ldots]$ Clearly, by this age the rate of acquisition of syntactic structures has decreased markedly, and differences between the child's grammar and adult grammar are no longer so readily discernible in the child's spontaneous speech. Such differences are brought to light, however, when we begin to explore the child's comprehension of particular syntactic structures ${ }^{9}$.

A pesar de la escasa investigación que se ha realizado sobre la adquisición del lenguaje en estas etapas tardías, es un hecho que el lenguaje infantil recibe un fuerte impulso en ellas: " a great

${ }^{7}$ El criterio fundamental para determinar el grupo social, se estableció desde 1976, con base en la ocupación y la escolaridad del jefe de la familia.

${ }^{8}$ Alfredo Hurtado ha definido como "estructuras tardías a aquellas representaciones gramaticales que se adquieren aproximadamente entre los siete y los nueve años' (Estructuras tardías en el lenguaje infantil, SEP-OEA, México, 1984, p. 1).

${ }^{9}$ CAROL ChOMSKY, The acquisition of syntax in children from 5 to 10, MIT Press, Cambridge, 1969, pp. 1 y 2. Véase también MaX Echeverría, Desarrollo de la comprensión infantil de la sintaxis española, Universidad de Concepción, Chile, 1978. 
deal of linguistic development occurs after 5 and well into the elementary school years"'10.

Precisamente, el experimento "Plática libre" se aplicó cuando los niños de la muestra estaban iniciando su primer año de primaria, momento interesante puesto que aún no recibían o empezaban a recibir el impacto de la lengua escrita, un factor que podría considerarse como determinante en el desarrollo de la sintaxis infantil.

Por último, el hecho de que la muestra esté formada por niños de tres grupos sociales permite hacer comparaciones entre las divergencias y similitudes de su producción y delimitar, por tanto, cuál es el hecho lingüístico en sí, y cuáles los otros factores que pueden influir en él.

\section{ANÁLISIS DEL CORPUS}

\section{La jerarquía de accesibilidad de Keenan y Comrie}

Después de un estudio tipológico de 50 leguas, Keenan y Comrie trataron de determinar las propiedades universales en la formación de oraciones relativas especificativas a las cuales definen, a partir de una noción básicamente semántica, de la siguiente manera:

We consider any syntactic object to be an RC if it specifies a set of objects (perharps a one-member set) in two steps; a larger set is specified, called the domain of relativization, and then restricted to some subset of which a certain sentence, the restricting sentence is true"'11.

Ellos distinguen estrategias en la formación de oraciones relativas según dos criterios. El primero se basa en el lugar que ocupan el núcleo o frase nominal y la oración relativa. Aquí hay tres posibles estrategias: la postnominal, en la cual el núcleo o frase nominal aparece antes de la relativa, como sucede en español:

\section{FN \\ OR \\ Mi hermana Malena la que viene a la escuela ${ }^{12}$}

${ }^{10}$ D. BRown, "Children's comprehension of relativized English sentences", Child development, Chicago, 42 (1971), p. 135.

${ }^{11}$ E. Keenan y B. Comrie, art. cit., pp. 63-64.

${ }^{12}$ Este ejemplo pertenece al experimento "Plática libre". 
La prenominal que es la estrategia de las lenguas donde la frase nominal aparece después de la oración relativa, como en el alemán:

$$
\begin{gathered}
\text { OR } \\
\text { der in seinem Büro arbeitende Mann } \\
\text { el en su estudio trabajando el hombre } \\
\text { 'el hombre que está trabajando en su estudio'13. }
\end{gathered}
$$

Y finalmente, la estrategia menos común, la interna, en donde la frase nominal aparece dentro de la misma oración relativa, como sucede en diegueño:

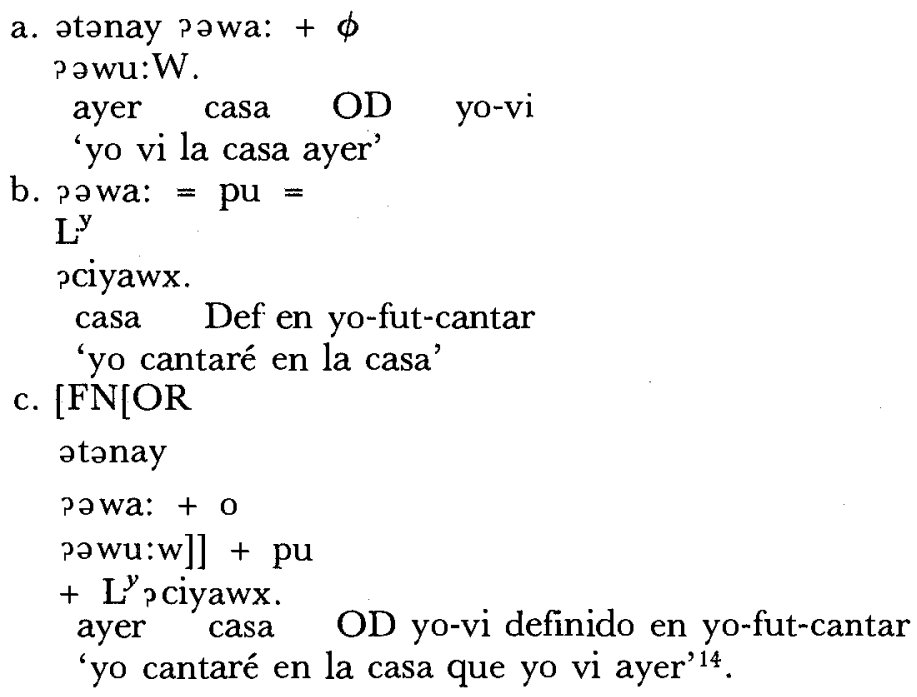

El segundo criterio para establecer estrategias en la formación de oraciones relativas se basa en la forma como se indica la posición de la frase nominal relativizada; aquí hay dos posibles estrategias; -caso y + caso. En la primera, no hay ninguna marca en la oración relativa que exprese qué posición se está relativizando, como en:

Una niña que ensaya en la escuela también tiene los ojos verdes ${ }^{15}$.

En este ejemplo la función del relativo que en la oración subordi-

\footnotetext{
${ }^{13}$ E. Keenan y B. Comrie, art. cit., p. 64.

${ }^{14}$ Id.

${ }^{15}$ Este ejemplo pertenece al experimento "Plática libre".
} 
nada es la de sujeto, pero no hay ningún elemento sintáctico dentro de ella que marque esta función. Por el contrario, en las construcciones que tienen una estrategia + caso, sí aparece un elemento que indica cuál posición de la frase nominal se está relativizando; este elemento duplica la función sintáctica que el relativo desempeña dentro de la oración subordinada, como en:

Hugo que él es el que lo trajo ${ }^{16}$,

donde el pronombre él marca al relativo que y duplica su función de sujeto ${ }^{17}$.

Para Keenan y Comrie, las lenguas se distinguen unas de otras con respecto a las posibles posiciones en que la frase nominal puede ser relativizada. Esta variación de lugar no es casual, pues la posibilidad de relativización de ciertas posiciones depende de otras, y estas dependencias son las que postulan como universales: "The accesibility hierarchy ( $\mathrm{AH})[\ldots]$ expresses the relative accessibility to relativization of NP positions in simplex main clauses" 18 .

La jerarquía de accesibilidad se expresa de la siguiente manera:

$$
\text { SU }>\text { OD }>\text { OI }>\text { OBL }>\text { GEN }>\text { OCOMP }
$$

donde $>$ indica que una posición a la izquierda de la jerarquía es más accesible que otra que esté a la derecha.

El sujeto (SU) es la posición más accesible y fácil de relativizar, y le siguen sucesivamente las posiciones del objeto directo (OD), el objeto indirecto (OI), el oblicuo (OBL), el genitivo (GEN) y el objeto de comparación (OCOMP).

La jerarquía de accesibilidad es, en resumen, "the set of possible grammatical distinctions to wich RC-formation may be sensitive"19. A partir de esta definición de la jerarquía, Keenan y Comrie postulan tres restricciones:

1) A language must be able to relativize subjects.

${ }^{16} \mathrm{Id}$.

17 Para algunos autores como Juan M. Lope Blanch, no existe tal duplicación de funciones, por el contrario, el relativo al aparecer marcado pierde su función. LOPE BLANCH llama a este fenómeno despronominalización y lo define como "el desdoblamiento funcional - mediante el cual el relativo actúa como simple nexo, en tanto que la función pronominal queda en cargo del pronombre o sustantivo en aposición-" ("La despronominalización de los relativos", $H L, 1,1984$, p. 259).

${ }^{18}$ E. Keenan y B. Comrie, art. cit., p. 66.

19 Ibid., p. 67. 
2) Any RC-forming strategy must apply to a continuous segment of the AH.

3) Strategies that apply at one point of the AH may in principle cease to apply at any lower point ${ }^{20}$.

Con una estrategia post nominal, de -caso y + caso, el español ocupa todos los lugares de relativización de la jerarquía, excepción hecha del objeto de comparación, según los datos de Keenan y Comrie:

Spanish

Relative clause

forming strategy

1. postnom, -case

2. postnom, + case

El objetivo de este trabajo será pues analizar la producción de relativas especificativas en niños de 6 a 7 años: qué estrategias siguen en la formación de relativas, en qué lugar de la jerarquía se encuentra su relativización, qué "errores" o construcciones particulares tienen, y qué relación tienen con el lugar de relativización, comprobar si realmente se cumplen en la sintaxis de las relativas de estos niños las tres restricciones postuladas por Keenan y Comrie, y si hay algún nexo evidente entre la producción y el grupo social.

\section{Las hipótesis}

$\mathrm{Al}$ iniciar el análisis de las oraciones relativas se plantearon varias hipótesis. La primera, que motivó el interés por este trabajo, fue que el nexo complejidad sintáctica-adquisición tardía es real: si la oración relativa es una oración de organización estructural compleja, hará su aparición tardíamente, y por lo tanto aún no formará parte de la sintaxis del niño de 6 a 7 años.

Muy cerca de esta hipótesis estaba la que nació de la jerarquía de Keenan y Comrie: lo que la jerarquía refleja tipológicamente es válido para la adquisición del lenguaje. El hecho de que todas las lenguas relativicen frases nominales en posición de sujeto implica que para una lengua esa posición es más fácil, y por tanto hará su aparición más tempranamente en el habla infantil; entonces, en los niños de la muestra, si la estructura relativa ya

${ }^{20} I d$.

21 Ibid., p. 79. 
hizo su aparición entre los 6 y 7 años, se esperaría que su producción fuera escasa y se limitara a las posiciones altas de la jerarquía, tal como lo postulan Keenan y Comrie: "The possibility of relativizing decreases as we go down the $\mathrm{AH}$, and in that sense, the further we descend the $\mathrm{AH}$ the harder it is to relativize" ${ }^{22}$.

Finalmente, por el tipo de muestra con la que se estaba trabajando, se podían plantear hipótesis basadas en la jerarquía también, pero con un criterio más sociolingüístico, del tipo código amplio y restringido ${ }^{23}$. Se podría postular que los niños del grupo social medio con un código amplio, y por tanto con más riqueza y alternativas sintácticas que el de los niños del grupo marginal, tendrían ocupadas más posiciones de relativización.

\section{Los problemas del análisis}

Una vez separadas del texto de la "Plática libre" todas las oraciones relativas especificativas, surgieron varios problemas en el análisis. Uno de ellos fue decidir la posición de relativización que ocupa la frase nominal; no siempre fue fácil determinar si era de sujeto, de objeto directo o de qué otra función: la forma un tanto caótica en que se organiza el discurso entre el niño y el investigador, la vaguedad del antecedente, la función del nexo en la oración principal y su función en la oración relativa, crearon serias confusiones en más de una ocasión. Para evitar posibles errores en el análisis y tener una mayor certeza y confianza en los resultados, se siguió la técnica de la "desrelativización". Se llamó así al proceso de recuperar la frase nominal que está elidida en la oración relativa pero que está señalada en el antecedente. Para recuperarla, de la oración compuesta con una subordinada relativa, se hacen dos oraciones. Por ejemplo, de la oración:

(s) $\mathrm{V} \quad \mathrm{OD} \quad \mathrm{SU} \quad \mathrm{OR}$

7.10 Tenían muchos hijos que se parecían a Pinocho ${ }^{24}$.

22 Ibid., p. 68.

${ }^{23}$ Cf. B. Bernstein, "Códigos amplios y códigos restringidos: sus orígenes sociales y algunas consecuencias", en Antologia de estudios de etnolingüistica y sociolingüistica, eds. P. L. Garvin y Y. Lastra de Suárez, UNAM, México, 1974, p. 357.

24 En adelante, cada vez que se haga referencia a una oración relativa de la "Plática libre", se hará de la siguiente manera: "7.10 Tenían muchos hijos que se parecían a Pinocho. SU", donde el 7 indica el número del niño o niña de la muestra, y el 10 el número de la oración relativa producida dentro de la "Plática libre". Así, 7.10 se refiere a José Manuel Córdoba López y a la 
se pueden derivar las oraciones:

(s) $\mathrm{V}$

$(\mathrm{s}) \mathrm{V}$

Tenían muchos hijos

y $\quad \mathrm{OD}$

Los hijos se parecían a Pinocho

SU $\quad \mathrm{O} \quad \mathrm{O}$

Esto permite ver con mayor claridad los constituyentes de cada oración y sus funciones de relación con la oración principal y dentro de la oración subordinada de relativo.

Otro de los problemas fue decidir qué se iba entender por oblicuo. Dentro de la jerarquía, ésta es la posición más vaga, puesto que Keenan y Comrie no la definen con precisión. En apariencia, esta posición podría interpretarse como aquella función que desempeñan los que no son ni objetos directos ni indirectos, tal como estos autores afirman al explicar la segunda restricción de su jerarquía - aquella que no permite saltos en los lugares de relativización"25: "Thus if a given strategy can apply to both subjects and locatives, it can also apply to DOs and IOs"'26. Esto significa que se incluye a los locativos dentro de los oblicuos. Si así fuera, no habría problema, al menos para el español, donde los locativos tienen una frecuencia considerable en la relativización ${ }^{27}$. Sin embargo, los autores, al definir lo que para ellos es oblicuo, excluyen precisamente a algunos locativos:

oración relativa número 10 que produjo. En el apéndice aparecen todas las oraciones relativas especificativas producidas por los niños de la muestra separadas en los tres grupos sociales ya mencionados. Inmediatamente después del nombre, entre paréntesis, está la edad del niño, que en este caso es de 6 años, 10 meses: José Manuel Córdoba López $(6,10)$.

Al final de cada oración están las iniciales de las palabras que representan la posición de relativización, en este caso sujeto (SU).

En general, se trató de poner no sólo la oración de relativo sino la principal a la cual estaba subordinada, y en ocasiones parte del contexto para dar una mayor claridad. En los casos en que la oración principal y el antecedente no aparecían en la plática del niño, sino en la del investigador, sólo se puso la oración de relativo producida por el niño. En todos los casos se respetó la forma de hablar de los niños.

25 Cf. supra, p. 113.

${ }^{26}$ E. Keenan y B.Comrie, art. cit., p. 67 (el subrayado es mío).

${ }^{27}$ Gf. F. Mendoza, "Sintaxis de los relativos en el habla popular de la ciudad de México", ALM, 22 (1984) 65-78; y M. Palacios, Sintaxis de los relativos en el habla culta de la ciudad de México, tesis, UNAM, México, 1979.

${ }^{28}$ E. KeEnan y B. Comrie, art. cit., p. 65. 
OBL for 'major oblique case NP' (we intend here NPs that express arguments of the main predicate, as the chest in John put the money in the chest rather than ones having a more adverbial function like Chicago in John lives in Chicago or that day in.John left on that day) ${ }^{28}$.

Con esta definición, Keenan y Comrie dividen todos aquellos complementos circunstanciales locativos o temporales del oblicuo $\mathrm{y}$, por tanto, los dejan sin lugar dentro de la jerarquía ${ }^{29}$.

Dada la vaguedad en la definición de Keenan y Comrie, el problema concreto para el análisis de las relativas de la "Plática libre." era decidir cómo se iba a interpretar esta definición. Había tres alternativas: la primera era considerar todo aquello que no fuera ni objeto directo ni indirecto como oblicuo. La segunda era tomar como oblicuos: a) aquellas construcciones en que apareciera una preposición acompañando al nexo relativo, interpretando la estrategia de construcción como + caso, como en

42.6 Cón los que juego son Salvador, Adolfo, Manuel, Pedrito y también Álvaro.

b) Aquellas construcciones donde apareciera un relativo cuyo antecedente tuviera un significado locativo o temporal como en:

$1.15^{*}$ Allá me voy a meter en la escuela que va a ir.

10.5 Una vez que echaron una piedra, le cayó a un niño.

En estas construcciones, la estrategia se consideró -caso, siguiendo a los autores que en su análisis las tratan como construcciones con preposición omitida ${ }^{30}$. Por último, analizar como complementos circunstanciales todas aquellas construcciones cuyo nexo fuera adverbio relativo de tiempo (donde) a de lugar (cuando), como en:

$20.7{ }^{*}$ La silla donde se sientan las niñas, la mamá les habla para comer.

${ }^{29}$ Bernard COMrIE, en estudios tipológicos posteriores a los de la jerarquía, reduce a cuatro las posiciones de relativización: SU $>$ OD $>$ OI $>$ GEN "Since these positions seem to form a cross-linguistically valid hierarchy with respect to relativization"' (Language universals and linguistic typology. Syntax and morphology, University of Chicago Press, Chicago, 1981, p. 149). En esta jerarquía no sólo desaparecieron los oblicuos, sino que definitivamente quedan fuera temporales y locativos: "Certain other positions, such as locatives and temporals do not seem to fit into this hierarchy: in some languages they are very easy to relativize, in other languages very difficult to relativize" (id.).

${ }^{30}$ Lope Blanch, art. cit.; F. Mendoza, art. cit.; y M. Palacios, op. cit. 
La tercera alternativa, por la que se optó, con base en la definición de Keenan y Comrie, es:

a) Tomar como oblicuos única y exclusivamente aquellas construcciones en que los niños hubieran relativizado frases nominales que formaran parte del argumento del predicado principal como en:

47.6 Nomás que no tenemos una cosa con que se solda el coche,

en donde con es inherente al verbo soldar y se vincula a cosa como argumento del predicado, y aparece marcando al relativo que, duplicando su función de oblicuo.

b) Llamar complemento circunstancial a todas aquellas construcciones con nexo pronominal o adverbial que relativizaran posiciones de tiempo, lugar, modo o cantidad, como en:

$42.3 *$ el otro día cuando vino Álvaro y yo.

6.4 *En una casita donde encierran los conejos, pero ya los mataron. 23.4 Lo vi un día que yo estaba malo.

8.2 *Fuimos a ver el pozo que se cayó una cubeta y la agarraba.

Quedaba aún por resolver el problema de asignarle un lugar en la jerarquía al complemento circunstancial, o bien dejarlo fuera de ella y sólo considerar aquellas posiciones propuestas por Keenan y Comrie. Aunque desde el punto de vista tipológico los circunstanciales no ocupan un lugar estable en la jerarquía, se decidió darles un lugar después del oblicuo, puesto que estructuralmente parecen ir primero los complementos más nucleares al verbo, como es el caso de los oblicuos, y después los menos nucleares.

La jerarquía, entonces, quedaba así:

$$
\mathrm{SU}>\mathrm{OD}>\mathrm{OI}>\mathrm{OBL}>\mathrm{CC}>\mathrm{GEN}
$$

Había que ver si los resultados apoyaban tal acomodo y si realmente el CC debía ocupar un lugar dentro de la jerarquía.

\section{LOS RESULTADOS A LA LUZ DE LA JERARQUía}

En el experimento "Plática libre" del Estudio Sociolingüístico de Lenguaje Infantil se encontraron 361 oraciones relativas especificativas, según se ve en la tabla número 1 .

Como se puede observar, estos resultados invalidan la primera hipótesis postulada sobre la ausencia o la escasez de la estructura relativa en los niños de 6 a 7 años, por ser ésta una estructu- 
Tabla 1

\begin{tabular}{cccccc}
\hline \multicolumn{2}{c}{ Grupo.obrero } & \multicolumn{2}{c}{ Grupo marginal } & \multicolumn{2}{c}{ Grupo medio } \\
\hline Niño & $\begin{array}{c}\text { Núm. de } \\
\text { relativas }\end{array}$ & Niño & $\begin{array}{c}\text { Núm. de } \\
\text { relativas }\end{array}$ & Niño & $\begin{array}{c}\text { Núm. de } \\
\text { relativas }\end{array}$ \\
\hline 1 & 29 & 21 & 4 & 41 & 8 \\
2 & 1 & 22 & $*$ & 42 & 10 \\
3 & 6 & 23 & 4 & 43 & 1 \\
4 & 3 & 24 & 2 & 44 & 3 \\
5 & 1 & 25 & 3 & 45 & 1 \\
6 & 7 & 26 & 6 & 46 & 5 \\
7 & 12 & 27 & 5 & 47 & 16 \\
8 & 3 & 28 & 2 & 48 & 3 \\
9 & 4 & 29 & 3 & 49 & 1 \\
10 & 7 & 30 & 3 & 50 & 8 \\
11 & 3 & 31 & $*$ & 51 & 11 \\
12 & 15 & 32 & 1 & 52 & 17 \\
13 & 4 & 33 & 4 & 53 & 3 \\
14 & 6 & 34 & 0 & 54 & 1 \\
15 & 1 & 35 & 1 & 55 & 6 \\
16 & 14 & 36 & 14 & 56 & 1 \\
17 & 4 & 37 & 3 & 57 & 5 \\
18 & 10 & 38 & 17 & 58 & 12 \\
19 & 5 & 39 & 3 & 59 & 14 \\
20 & 7 & 40 & 12 & 60 & 0 \\
& & & & 61 & 6 \\
\hline Total & 142 & Total & $\mathbf{8 7}$ & Total & 132 \\
\hline
\end{tabular}

* Fuera de la muestra, se negó a hablar.

ra compleja y por tanto de aparición tardía. Es evidente que el niño de 6 a 7 años ya tiene en su inventario la estructura de relativo; un promedio de $5.92 \%$ oraciones relativas por niño apoya esta afirmación ${ }^{31}$.

En cuanto a las posiciones de relativización en la jerarquía hubo resultados interesantes. Como se puede ver en las tablas 2 a 5, de las 361 oraciones relativas de la "Plática libre", 226 relativizaron el sujeto, o sea un $62.60 \%$ del total de oraciones; 68 oraciones, el $18.83 \%$ del total, relativizaron OD. Hasta aquí los resultados eran predecibles y sostenían las hipótesis planteadas. Lo

31 Pese a los resultados, cabe cuestionarlos. ¿El que los niños produzcan relativas significa que realmente las comprenden, las dominan en toda su variedad estructural? ¿Qué tan lejos o cerca están del modelo adulto? ¿Qué tantos de sus "errores" son en realidad construcciones transitorias y particulares de un estado específico de lengua? Se tratará de contestar algunas de estas preguntas; otras requieren, sin duda, de más investigación para encontrar una respuesta sólida. Cf. infra, pp. 126 ss. 
Tabla 2

POSICIONES DE RELATIVIZACIÓN POR GRUPO

\begin{tabular}{crrrrrr}
\hline \multicolumn{7}{c}{ Obrero } \\
\hline Niño & \multicolumn{1}{c}{$S U$} & OD & OI & CC & OBL & GEN \\
\hline 1 & 14 & 5 & 3 & 6 & - & - \\
2 & 1 & - & - & - & - & - \\
3 & 6 & - & - & - & - & - \\
4 & - & 2 & - & 1 & - & - \\
6 & 1 & - & - & - & - & - \\
7 & 3 & 3 & - & 1 & - & - \\
8 & 10 & 2 & 1 & - & - & - \\
9 & 4 & - & - & 1 & - & - \\
10 & 1 & 1 & - & 5 & - & - \\
11 & 3 & - & - & - & - & - \\
12 & 11 & 1 & 1 & 2 & - & - \\
13 & 4 & - & - & - & - & - \\
14 & 3 & 1 & - & 2 & - & - \\
15 & - & - & - & 1 & - & - \\
16 & 9 & 4 & 1 & - & - & - \\
17 & 2 & 2 & - & - & - & - \\
18 & 7 & - & - & 2 & 1 & - \\
19 & 5 & - & - & - & - & - \\
20 & 4 & - & - & $\frac{3}{2}$ & - & - \\
$\frac{\text { Total }}{15}$ & 89 & 22 & 6 & 24 & 1 & 0 \\
\hline
\end{tabular}

interesante empieza cuando se observan las cifras que alcanzaron las demás posiciones de la jerarquía. Si bien es cierto que algunas son bajas, no por ello dejan de ser reveladoras.

Inmediatamente después de las oraciones que relativizaron OD siguen las que relativizaron un CC (12.18\%), luego las oraciones que relativizaron or $(3.87 \%)$. Las oraciones que relativizaron OBL tan sólo alcanzaron el $2.21 \%$; finalmente, la cifra más baja corresponde al único genitivo del corpus, con un $.27 \%$.

Según estos resultados, el lugar tentativo que se había asignado el CC dentro de la jerarquía no resultó ser el justo; seguiría inmediatamente al OD, y no al OBL, como se había supuesto.

La jerarquía de relativización en estos niños, siguiendo un criterio de frecuencia relativa y no tipológico, quedaría así:

$\mathrm{SU}>\mathrm{OD}>\mathrm{CC}>\mathrm{OI}>\mathrm{OBL}>\mathrm{GEN}$

Cabe señalar que los resultados hubieran sido muy diferentes si se hubiera adoptado cualquiera de las alternativas que se men- 


\begin{tabular}{lrrrrrr}
\multicolumn{7}{c}{ Tabla 3 } \\
\hline \multicolumn{7}{c}{ Margïnal } \\
\hline Niño & $S U$ & OD & OI & CC & OBL & GEN \\
\hline 21 & 1 & - & - & 1 & 2 & - \\
22 & - & - & - & - & - & - \\
23 & 2 & I & - & I & - & - \\
24 & - & 2 & - & - & - & - \\
25 & 1 & - & 2 & - & - & - \\
26 & 2 & - & - & 2 & 2 & - \\
27 & 5 & - & - & - & - & - \\
28 & 2 & - & - & - & - & - \\
29 & 1 & 2 & - & - & - & - \\
30 & 2 & 1 & - & - & - & - \\
31 & - & - & - & - & - & - \\
32 & 1 & - & - & - & - & - \\
33 & 4 & - & - & - & - & - \\
34 & - & - & - & - & - & - \\
35 & - & 1 & - & - & - & - \\
36 & 11 & 2 & 1 & - & - & - \\
37 & 3 & - & - & - & - & - \\
38 & 13 & - & - & 4 & - & - \\
39 & 3 & - & - & - & - & - \\
40 & 4 & 7 & 1 & - & - & - \\
$\frac{40}{\text { Total }}$ & 55 & 16 & 4 & 8 & 4 & 0 \\
\hline
\end{tabular}

cionaron antes ${ }^{32}$. Es interesante mencionar los posibles resultados. En la primera alternativa, las posiciones en la jerarquía hubieran quedado así:

$\mathrm{SU}>\mathrm{OD}>\mathrm{OBL}>\mathrm{OI}>\mathrm{GEN}$

en donde la posición del OI no correspondería al orden propuesto por Keenan y Comrie.

Si se hubiera seguido la segunda de las alternativas, los lugares quedarían así:

\section{$\mathrm{SU}>\mathrm{OD}>\mathrm{OBL}>\mathrm{OI}>\mathrm{ADV}$ REL $>$ GEN}

Como se ve en esta jerarquía, el or tampoco ocupa el lugar previsto por Keenan y Comrie, además de que habría que asignarles un lugar a los adverbios relativos (locativos y temporales), que considerados independientes alcanzaron el mismo porcentaje de 
Tabla 4

\begin{tabular}{lrrrrrr}
\hline \multicolumn{7}{c}{ Medio } \\
\hline Niño & $S U$ & OD & OI & CC & OBL & $G E N_{\mathrm{i}}$ \\
\hline 41 & 4 & 1 & 2 & - & - & - \\
42 & 6 & 1 & 1 & 1 & 1 & - \\
43 & - & - & - & 1 & - & - \\
44 & 1 & 2 & - & - & - & - \\
45 & 1 & - & - & - & - & - \\
46 & 4 & 1 & - & - & - & - \\
47 & 11 & 3 & - & 1 & 1 & - \\
48 & 1 & 2 & - & - & - & - \\
49 & - & 1 & - & - & - & - \\
50 & 4 & - & 1 & 3 & - & - \\
51 & 8 & 3 & - & - & - & - \\
52 & 12 & 4 & - & 1 & - & - \\
53 & 1 & 1 & - & - & 1 & - \\
54 & 1 & - & - & - & - & - \\
55 & 4 & 2 & - & - & - & - \\
56 & - & - & - & 1 & - & - \\
57 & 4 & 1 & - & - & - & - \\
58 & 5 & 5 & - & 2 & - & - \\
59 & 10 & 3 & - & 1 & - & - \\
60 & - & - & - & - & - & - \\
61 & 5 & - & - & 1 & - & - \\
$\frac{7}{\text { Total }}$ & 82 & 30 & 4 & 12 & 3 & 1 \\
\hline
\end{tabular}

Tabla 5

TOTAL DE POSICIONES DE RELATIVIZACIÓN

\begin{tabular}{lrr}
\hline & Totales & Porcentajes \\
\hline SU & 226 & 62.60 \\
OD & 68 & 18.83 \\
OI & 14 & 3.87 \\
CC & 44 & 12.18 \\
OBL & 8 & 2.21 \\
GEN & 1 & 0.27 \\
& 361 & \\
\hline
\end{tabular}

frecuencia que los OI: $3.87 \%$, o bien dejarlos fuera.

De estos posibles resultados, el que más se apegaría a la distribución propuesta por Keenan y Comrie sería el de la tercera alternativa, que fue la seguida en este análisis. Como ya se vio, el orden quedaría de la siguiente manera: 
donde el complemento circunstancial ocupa un lugar que no viene de las pautas de Keenan y Comrie, sino que fue puesto arbitrariamente. Al quitarlo de la jerarquía los resultados se apegarían a lo propuesto por dichos autores:

\section{$\mathrm{SU}>\mathrm{OD}>\mathrm{OI}>\mathrm{OBL}>\mathrm{GEN}$}

Sin embargo, es un hecho que el español — no sólo en el habla infantil sino en la adulta y popular ${ }^{33}$ - es una lengua que relativiza con facilidad locativos y temporales ${ }^{34}$.

Sea cual fuere el acomodo de los lugares en la jerarquía, lo interesante es observar la relación producción-complejidad. Si bien es cierto que la producción en las posiciones de sujeto y objeto directo no fue escasa como se había hipotetizado, también lo es que la producción disminuye considerablemente en tanto van bajando las posiciones en la jerarquía. En este sentido se validan tanto la hipótesis que se habían planteado como las afirmaciones de Keenan y Comrie ${ }^{35}$. Pero habría que profundizar mucho aún para poder afirmar si realmente la frecuencia está relacionada con la complejidad estructural de una oración o se trata de una característica interesante del sistema de la lengua, que así se organiza independientemente de la adquisición temprana o tardía, y de las realidades del habla infantil y del habla adulta.

\section{Estrategias de relativización}

Con respecto a las estrategias seguidas por los niños al relativizar, se encontraron los resultados que aparecen en la tabla 6.

Tabla 6

\begin{tabular}{crrrrrr}
\hline Estrategia de formación & $S U$ & $O D$ & $O I$ & $C C$ & $O B L$ & $G E N$ \\
\hline postnominal - caso & 225 & 68 & - & 43 & - & - \\
postnominal + caso & 1 & - & 14 & 1 & 8 & 1 \\
\hline
\end{tabular}

Como se puede observar, todos los niños relativizaron con una estrategia postnominal: la frase nominal en las 361 oraciones especificativas, aparece siempre antes de la relativa, como en:

${ }^{33}$ Cf. F. Mendoza, art. cit. y M. Palacios, op. cit.

${ }^{34}$ Véase n. 29.

35 Cf. supra, p. 114. 


$$
\mathrm{F}-\mathrm{N}
$$

1.13 Unos amigos que tengo ahí en la escuela, me llevan a ver una película.

$\mathrm{N}$

Estos resultados están de acuerdo con los datos que Keenan y Comrie dan para el español ${ }^{36}$. En cuanto a la estrategia que indica la posición relativizada ( + caso -caso), se encontraron 336 oraciones $(93.07 \%)$ con estrategia -caso: ningún elemento sintáctico aparece marcando la función del relativo como en:

20.2 Una muñeca que se llama enfermera, cura bien a los enfermos.

Las otras 25 oraciones $(6.93 \%)$ se relativizaron con una estrategia + caso.

En la oración

51.4 Hugo que él es el que lo trajo,

la posición de sujeto aparece relativizada con una estrategia + caso, contraria a los datos de Keenan y Comrie ${ }^{37}$, según los cuales el español sólo relativiza sujetos con estrategia -caso.

Las 14 oraciones que se relativizaron en la posición de objeto indirecto contradicen totalmente a Keenan y Comrie, para quienes en español el objeto indirecto se relativiza con una estrategia - cas $^{38}$. En todas ellas aparece el pronombre le marcando al relativo ${ }^{39}$, como en:

1.1 * Mire, primero empezó de Pedro Infante y la muchacha que le decía la chorreada.

Los resultados para el oblicuo y el genitivo coinciden con los datos de Keenan y Comrie ${ }^{40}$. Aparecen en este corpus 8 oraciones que relativizan oblicuo con estrategia +caso, como en:

18.7 Con la cubeta que le echó el gato el agua al lobo[...],

36 Cf. supra, p. 114.

${ }^{37} \mathrm{Id}$.

${ }^{38} I d$.

${ }^{39}$ LOPE BLANCH encuentra "relativamente en el español mexicano la despronominalización del relativo con función de complemento indirecto" (art. cit., p. 260). Esto viene a confirmar que los datos de Keenan y Comrie para la estrategia de relativización del objeto indirecto están equivocados.

${ }^{40}$ Cf. supra, p. 114. 
en donde la preposición con, desplazada, está marcando al relativo que y duplica su función sintáctica de oblicuo.

Aparece una oración en el corpus en donde el relativo ocupa la posición de genitivo con estrategia + caso:

41.2 Una niña güera que es s̀u cumpleaños y no sé cuántos cumple.

A pesar de la marginalidad de este ejemplo, coincide con los datos de Keenan y Comrie ${ }^{41}$.

Finalmente, aparece en el corpus una oración que relativiza un locativo con estrategia + caso:

26.6 * Tengo una estufita de onde poníamos cosas, las cositas,

en la cual la preposición de usada anómalamente (correspondería el uso de en) está marcando al relativo onde y duplica su función.

\section{Las restricciones}

De las tres restricciones postuladas por Keenan y Comrie a su jerarquía ${ }^{42}$, sólo se viola la segunda en las relativas producidas por los niños de esta muestra.

Como ya vimos, esta restricción establece que cualquier estrategia en la formación de relativas debe aplicarse a una sección continua de la jerarquía y por tanto no debe haber saltos en las posiciones: si se relativiza un sujeto y un objeto indirecto con estrategia - + caso, necesariamente se relativizará un objeto directo, pues de lo contrario se viola la jerarquía.

Según los resultados obtenidos en la "Plática libre", la jerarquía quedaría frente a la Keenan y Comrie como aparece en la tabla número 7 .

Tabla 7

KEENAN Y COMRIE

\begin{tabular}{cccccccc}
\hline Estrategia de formación & $S U$ & $O D$ & $O I$ & $C C$ & $O B L$ & $G E N$ \\
\hline $\begin{array}{c}\text { postnominal -caso } \\
\text { postnominal + caso }\end{array}$ & + & + & + & - & - & - & - \\
\hline \multicolumn{7}{c}{ "PLÁTICA LIBRE" } \\
\hline Estrategia de formación & $S U$ & $O D$ & $O I$ & $C C$ & $O B L$ & OEN \\
\hline postnominal -caso & + & + & - & + & - & - \\
postnominal + caso & + & + & + & + & + & + \\
\hline
\end{tabular}

${ }^{41}$ Id. En el habla culta adulta se contradiría este dato, pues el uso de cuyo para el genitivo sigue una estrategia -caso (cf. M. PAlacios, o.p. cit.).

42 Cf. supra, p. 113. 
Como se puede observar, las estrategias -+ caso no se aplican a segmentos continuos de la jerarquía. Si se toma en cuenta la posición del complemento circunstancial, la continuidad se rompe precisamente en la posición de circunstancial en la estrategia -caso, y en el objeto directo en la de + caso; si se elimina al circunstancial de la jerarquía, la estrategia + caso sufre un salto en la posición del objeto directo.

\section{La producción de relativos en relación con el grupo social}

Finalmente queda por ver los resultados relacionados con el grupo social de los niños. Las hipótesis se cumplieron en forma parcial: se realizaron ciertas expectativas, pero resultaron algunas cosas contrarias a lo esperado. Así, como se puede ver en las tablas 8 y 9 , se verificó que la producción más baja de relativas corresponde a los niños del grupo marginal con 87 oraciones $(24.10 \%)$. Sin embargo, aunque muy cercanos en su producción, los niños del grupo obrero con 142 oraciones (39.34\%) superaron a los del medio con 132 (36.55\%). Esto no responde a la expectativa de un grupo medio con una producción, en general, más rica que la de los demás grupos sociales.

\section{Los "errores" o construcciones particulares de los niños}

A pesar de que los "errores" 43 o construcciones particulares que se encontraron en las oraciones de relativo de los niños no afectaban en su gran mayoría el análisis de posiciones de relativización, es importante mencionarlos pues dan cierta luz para interpretar algunos hechos de la adquisición de sintaxis infantil. Estas construcciones particulares podrían ser el reflejo de estados transitorios en la formación de su sintaxis, como parte del proceso que lleva a su competencia lingüística general:

There is really no way to determine if the child's utterances are grammatically non deviant in terms of his own grammar. And even if the grammatically nondeviant utterances could be reliably deter-

43 Dado que error se puede definir de muchas maneras, desde aquello que no está construido conforme a una gramática del adulto, desviaciones de la norma, hasta falsos inicios, dubitaciones, etc., se decidió llamar a todas aquellas construcciones de los niños que presentaron alguna anomalía (desde el punto de vista adulto) "construcciones particulares". En el apéndice aparecen marcadas con un asterisco todas aquellas construcciones, tanto de la oración relativa como de la principal, que presentan algún problema. 
Tabla 8

POSICIONES DE RELATIVIZACIÓN POR GRUPO

\begin{tabular}{|c|c|c|c|c|}
\hline & Obrero & Marginal & Medio & Total \\
\hline SU & 89 & 55 & 82 & 226 \\
\hline OD & 22 & 16 & 30 & 68 \\
\hline OI & 6 & 4 & 4 & 14 \\
\hline CC & 24 & 8 & 12 & 44 \\
\hline OBL & 1 & 4 & 3 & 8 \\
\hline GEN & 0 & 0 & 1 & 1 \\
\hline & 142 & 87 & 132 & 361 \\
\hline \multicolumn{5}{|c|}{ PORCENTAJE DE POSICIONES DE RELATIVIZACIÓN POR GRUPO } \\
\hline & Obrero & Marginal & Medio & \\
\hline SU & 62.67 & 63.22 & 62.12 & \\
\hline OD & 15.49 & 18.40 & 22.73 & \\
\hline OI & 4.22 & 4.60 & 3.03 & \\
\hline OBL & 0.7 & 4.60 & 2.27 & \\
\hline $\mathrm{CC}$ & 16.90 & 9.19 & 9.09 & \\
\hline GEN & 00 & 00 & 0.75 & \\
\hline
\end{tabular}

Tabla 9

Oraciones Relativas

\begin{tabular}{lccc}
\hline & Totales & $\begin{array}{c}\text { Porcentaje } \\
\text { del total }\end{array}$ & $\begin{array}{c}\text { Porcentaje de relativas } \\
\text { por niño (por grupo) }\end{array}$ \\
\hline Grupo obrero & 142 & 39.34 & 7.15 \\
Grupo marginal & 87 & 24.10 & 4.35 \\
Grupo medio & $\underline{132}$ & $\underline{36.55}$ & $\underline{6.28}$ \\
Total & 361 & & \\
\hline
\end{tabular}

mined, they could only give hints as to the total grammatical capacity of the child ${ }^{44}$.

En las oraciones relativas de la "Plática libre" se encontró un total de 67 construcciones particulares: 33 en el grupo obrero, 17 en el grupo marginal y 17 en el grupo medio.

Los problemas encontrados en estas construcciones se reducen concretamente a:

1) Falta de concordancia, como en:

$1.15^{*}$ Allá me voy a meter en la escuela que va a ir.

44 D. SLOBin, "Syntactic regularities of the speech of children", en Studies of child language development, p. 334. 
2) Omisión ${ }^{45}$ de algún elemento gramatical, como en:

$47.3 *$ Nada más que como ese tiene algo donde [si] lo tocas se calienta.

$8.2{ }^{*}$ Fuimos a ver el pozo [en] que se cayó la cubeta ${ }^{46}$ y la agarraba.

3) Aparición de un elemento gramatical de más dentro de la estructura, como en:

$7.8 * \mathrm{El}$ más chico agarraba cosas de que eran de vidrio.

4) Construcciones incompletas, como en:

$1.20{ }^{*}$ El que, el que, cómo se llama, el viejo de las tortillas [E] que vende tortillas], bueno, un día se pelió con una señora.

5) Construcciones incoherentes, como en:

9.4 * Si rompen un vidrio que ya está muy grande, grande el niño.

Como se puede ver, la mayoría de estos problemas (1-3) está en estrecha relación con la organización sintáctica de la oración, en tanto que los dos últimos (4-5) apuntarían a un desconocimiento léxico o a una desorganización semántica, por llamarlo de alguna manera.

Otra forma de enfocar estas construcciones particulares es en relación con la posición relativizada. La suposición más lógica sería que se encontrarían problemas o peculiaridades en las posiciones más bajas, y por tanto más difíciles, de la jerarquía. Contrario a esto, el mayor número de particularidades se encontró en la posición de SU (tabla número 10), la más fácil, común, universal y supuestamente la de adquisición más temprana de todas las posiciones. De las construcciones encontradas con particularidades, más del $50 \%$ fueron de $\mathrm{SU}$, frente a 5 de OBL, la posición más baja y más compleja de la jerarquía.

En cuanto a la posición OD, se encontraron 9 construcciones

${ }^{45}$ Las oraciones como 1.11: "El día [en] que le dieron el regalo yo no fui", en donde la preposición en se omite, no se consideraron como construcciones particulares de los niños, ya que esta omisión parece ser un hecho del español. Cf. M. PALACios, op. cit.; y F. Mendoza, art. cit., p. 69.

${ }^{46}$ El problema de esta construcción también podría deberse al uso de un nexo equivocado: que por donde. 
Tabla 10

CONSTRUCCIONES PARTICULARES

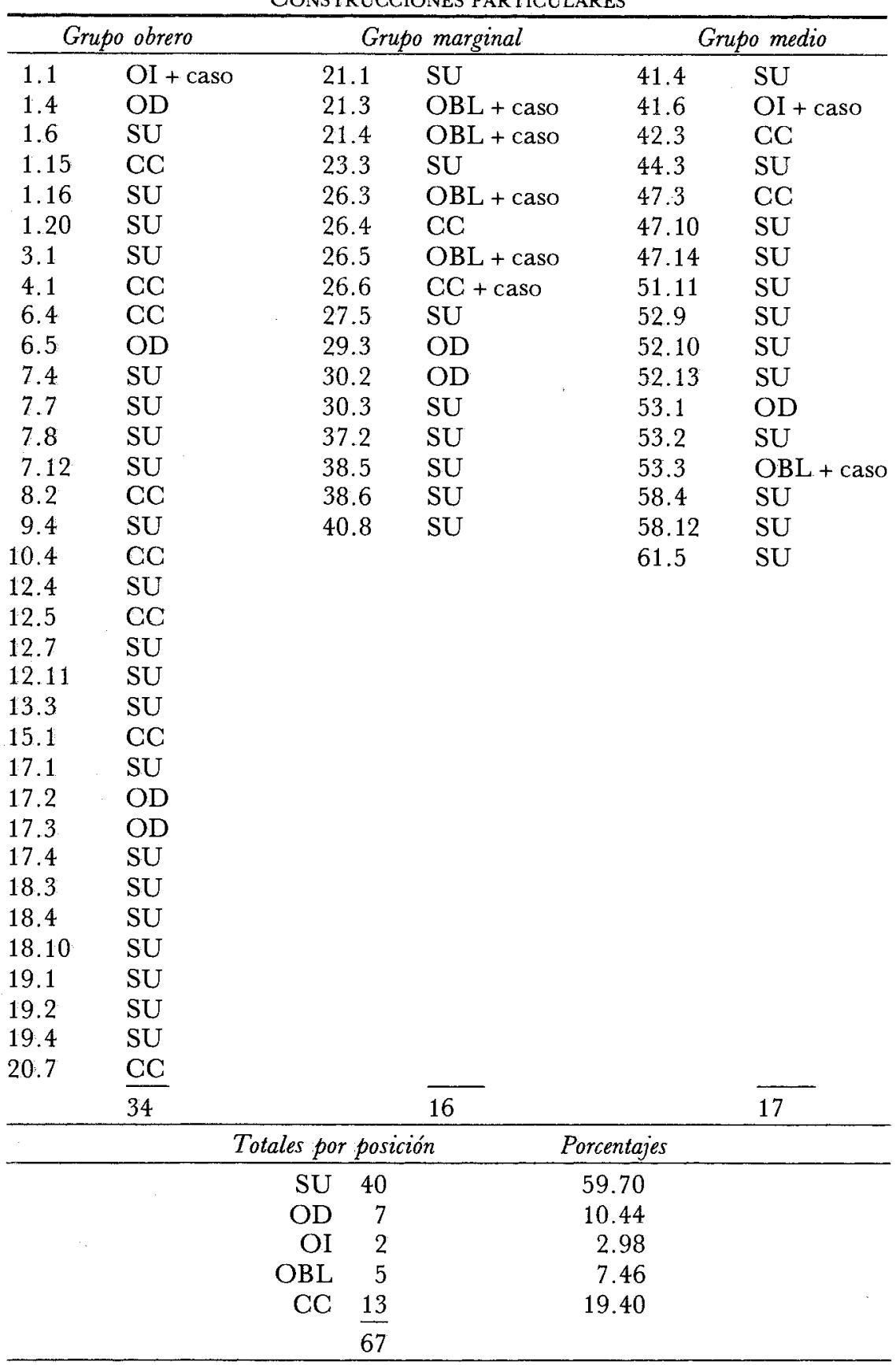


particulares, pocas en relación con la de SU. Esta posición tiene un interés especial, ya que hay pruebas de su dificultad en el nivel de la comprensión:

We have chosen to focus on self-embedded relative clauses (subject and object) for which structural differences have rather consistently yielded different processing difficulties, subject relatives have been shown to be easier than object relatives to comprehend (Fodor, Bever and Garret, 1974, Wanner and Maratsos, 1978) ${ }^{47}$.

Max Echeverría encontró en su estudio que "la comprensión de las oraciones subordinadas adjetivas resultó una tarea sumamente difícil para nuestros sujetos" ${ }^{48}$. Esta dificultad se centraba concretamente en la asignación de funciones sintácticas a oraciones relativas cuya posición relativizada ocupaba un objeto directo, tal como en:

El pato que empujó Pedrito se puso a llorar ${ }^{49}$.

Aquí surge un problema muy interesante y complejo: ¿producir una oración significa comprenderla? Durante mucho tiempo se ha afirmado que la comprensión precede a la producción;

The assertion that understanding precedes production can be taken to mean that some utterances are ordinarily understood before any utterances are produced. There is strong empirical support for this thesis if we are willing to accept the production of an appropriate response as evidence that an utterance has been understood ${ }^{50}$.

Todo esto implica que si el niño produce una oración es porque la comprende. Sin embargo, de las particularidades encontradas en este corpus y las demás pruebas mencionadas, se puede suponer que hay niveles en el dominio de una lengua; que producir una estructura no necesariamente significa manejarla del todo y comprenderla en su plenitud.

Carol Chomsky ha demostrado que los niños entienden ciertas estructuras parcialmente y que las interpretan de acuerdo con

47 Frandfelder, Segui, y Mehler, "Monitoring around the relative clause", JVLVB, 1980, núm. 19, p. 229.

48 Op. cit., pp. 115-134.

49 Ibid., p. 118.

50 C. Fraser, U. Bellugi y R. Brown, "Control of grammar inmitation, comprehension and production", en Studies of child language develdpment, p. 466. 
el grado de desarrollo lingüístico que tienen: “'They understand them, but they understand them wrongly" 51.

Por tanto, el que los niños hayan tenido pocos problemas en la producción de oraciones que relativizaron objetos directos no es la prueba más confiable del dominio en la relativización de este lugar de la jerarquía.

Otro lugar interesante con problemas de construcción es el del oblicuo. Como ya habíamos visto, la clase marginal había producido, pese a lo esperado por su dificultad estructural, varias oraciones en esta posición, pero lo relevante es que todas presentan alguña particularidad en su construcción que habla de una irregularidad en su manejo.

Otra relación interesante es la de construcciones particularesgrupo social. Como se ve en la tabla 10, el mayor número de problemas se produjo en el grupo obrero, donde se encontró también una mayor producción de oraciones relativas dentro del corpus, otra prueba más para apoyar la afirmación de que producir no siempre es sinónimo de dominar.

Con respecto al grupo marginal, cabe preguntarse si el que haya tenido menor número de problemas en sus construcciones que el grupo obrero tiene que ver con su competencia o con la características peculiares de su habla. Es evidente la diferencia que se percibe en la "Plática libre" entre el habla de los niños del grupo obrero y medio frente a la del grupo marginado. El habla de los primeros se caracteriza por una mayor fluidez y confianza frente a la parquedad de los otros dos grupos. Así que el hecho de que la relativa esté ya presente en los niños de 6 a 7 años tal vez no sea el mejor criterio para afirmar que hay un dominio absoluto de ella. Aquí cabría la posibilidad de una nueva hipótesis: las estructuras de organización formal compleja como la relativa se van adquiriendo paulatinamente, con una asimetría en los niveles de comprensión y producción hasta lograr un equilibrio en las dos dimensiones. Ese equilibrio sería sin duda el arribo a la competencia sintáctica.

Variaciones estructurales en las oraciones relativas de los niños de la "Plática libre"

Por último, aunque el objetivo de este trabajo era el análisis de los datos con base en la jerarquía de Keenan y Comrie, cabe hacer el análisis del tipo de relativas que producen los niños fren-

51 C. Chomsky, op. cit., p. 2. 
te al de los adultos, para tener una visión lo más amplia posible y poder, además, deslindar lo que es producción realmente infantil de lo que no lo es.

De entre las 361 oraciones relativas de la "Plática libre", se encontró lo siguiente:

I. Tipos de nexo:

1. Pronombre relativo que

2. Pronombre relativo quien

3. Adverbio relativo donde

4. Adverbio relativo cuando

II. Tipos de construcción:

1. Construcciones con antecedente, como en:

20.2 Una muñeca que se llama enfermera, cura bien a los enfermos.

2. Construcciones sin antecedente: $($ Art + que $)$ :
A. Sujetivas, como en:

18.9 La que es mujer se va con niña mujer.

B. Objetivas, como en:

4.2 Es que no sé hacer lo que hace él.

C. Predicativas, como en:

30.1 Nada más todo eso fue lo que pasó.

D. Circunstanciales:
a) De lugar, como en:

21.4 * Mi hermano tenía uno d'esos con los que sube un pie.

b) Instrumento, como en:

21.3 Se le rompió la, con lo que maneja

c) Compañía, como en:

42.6 Con los que juego son Salvador, Adolfo, Manuel, Pedrito y también Álvaro. 
E. Adnominales, como en:

29.2 Ya hicimos tarea de lo que pone en el pizarrón.

3. Construcciones con antecedente duplicado, preservando su función en la oración relativa, como en:

16.12 Y un hada madrina que siempre se le aparecía a Caperucita la hada madrina.

4. Construcciones con pronombre relativo, como en:

27.1 Mi mamá come junto con una señora que vive en mi casa.

5. Construcciones con preposición, como en:

$21.4^{*} \mathrm{Mi}$ hermano tenía un d'esos, con los que sube un pie.

6. Construcciones con preposición omitida, como en:

12.4 * Mi hermano le regaló unas [en] que se echan tijeras, abujas.

7. Construcciones con preposición desplazada, como en:

18.7 Con la cubeta que le echó el agua al lobo.

8. Construcciones sin preposición, como en:

1.21 Es que un día que no fui

1.22 que se me olvidó traerlas, ya no quiso.

9. Construcciones con adverbio relativo, como en:

$6.4 *$ En una casita donde encierran los conejos, pero ya los mataron.

10. Construcciones con aposiciones, como en:

33.2 La Cruz Roja, la que se llevó al viejito ese, se llevó al señor.

III. Relaciones interoracionales:

1. Entre relativas

A. Yuxtaposición con el mismo antecedente, como en: 
1.21 y 22 Es que un día que no fui que se me olvidó traerlas, ya no quiso.

B. Yuxtaposición con diferente antecedente, como en:

1.17 y 18 La paleta que hice allá en la esa donde está la casita.

C. Coordinación con el mismo antecedente, como en:

14.2 y 3 La otra véz que estaba yo sentado y que estaba yo allá, le estaba poniendo la grabadora.

D. Coordinación con diferente antecedente, como en:

39.1 y 2 Es uná que se llama Nacha y otra que se llama Mosco.

2. Entre relativas y otras oraciones subordinadas, como en:

55.1 y 2 Había una vez una abejita, la que nos dijo la maestra, que estaba muy pero muy aburrida.

Estas relaciones interoracionales son las construcciones más interesantes. La complejidad estructural que tienen haría pensar que aún no forman parte de la sintaxis de relativo del niño, pues definitivamente representan un nivel mayor de dificultad en la producción que otros tipos de oraciones con relativas. Puesto que entre el antecedente y el nexo median relaciones sintácticas de diferente naturaleza, surge la pregunta de si el niño realmente comprende estas construcciones en su totalidad. También cabría pensar que en su construcción habría particularidades, pero no sucede así. No se puede decir que sean sumamente escasas, pues dentro de la muestra alcanzan mayor número que otras construcciones al parecer menos complejas.

Además de estos tipos de oraciones claramente clasificables, se encuentran peculiaridades debidas quizá a la situación de discurso en que se efectuaba el experimento, a realidades de la lengua hablada, o simplemente a un rasgo distintivo del habla infantil. Por ejemplo, en el corpus se encuentran varias oraciones relativas de los niños cuya oración principal, o no aparece nunca como en:

16.11 El pecoso y el otro señor que no querían al lobo y al zorrito.

${ }^{52}$ En el apéndice aparecen señaladas con un círculo que encierra la posición de relativización. 
o se encuentra implícita en la pregunta del investigador, como en:

1.26 I. ¿'Te dan miedo los doctores?

N. Sí, pero los que vacunan.

En otras ocasiones, hay oraciones del niño en donde el antecedente está en la oración del investigador, como en:

$7.6 \mathrm{I}$. ¿Y cómo es su carro?

N. Que no tiene techo, así.

Esta tipología infantil de oraciones relativas en relación con la encontrada en el habla adulta culta y popular de la ciudad de México ${ }^{53}$ muestra que, en términos generales, la sintaxis de relativo en el habla de los niños es muy semejante a la del habla adulta. En cuanto a los nexos, salvo el cual y la cual, que aparecen tanto en el habla adulta culta y popular, y como, que aparece sólo una vez en el habla culta, los niños usan los mismos que los adultos. Los tipos de construcción también son los mismos; y de las clases de oraciones introducidas por la forma art + que, encontradas por Francisco Mendoza en el habla popular, sólo cinco, poco frecuentes a decir del autor, no aparecen en los niños: prepositivas, indirectas, causales, comparativas y finales.

En los adultos como en los niños, más o menos en la misma proporción, aparecen construcciones con preposición, sin preposición y con adverbios.

Las funciones del relativo en la oración subordinada se encuentran también en la misma proporción.

Margarita Palacios encontró en el habla culta adulta relaciones de yuxtaposición y coordinación en las relativas, iguales a las que aparecen en las oraciones de los niños.

El único tipo de construcción que no menciona ni Francisco Mendoza ni Margarita Palacios en sus estudios del habla adulta y que aparece en la tipología infantil es el de aquellas oraciones relativas que se relacionan con otros tipos de oraciones subordinadas.

Todas estas similitudes entre las relativas del habla adulta y del habla infantil, como ya se había dicho anteriormente, son muy interesantes en tanto que esclarecen muchos puntos con respecto a lo que realmente pertenece al habla del niño y lo que es un hecho del sistema sintáctico del español de México $^{54}$. Si la gramá-

${ }^{53}$ Cf. F. Mendoza, art. cit.; y M. Palacios, op. cit.

${ }^{54}$ Lo que en principio se pensó complejo para el niño y por lo tanto es- 
tica adulta es el último punto al cual se dirige la gramática del niño, se puede decir - al menos a la luz de los resultados de este estudio y los del habla adulta mencionados- que el niño ya adquirió el esqueleto básico de la estructura relativa. Sus construcciones particulares hablan de cuál es la sustancia que aún le hace falta a ese esqueleto para adquirir cuerpo; hablan también de las etapas transitorias por las que un niño va pasando antes de alranzar su competencia sintáctica.

En términos de complejidad estructural, quizá lo último en conformar el cuerpo de las relativas serán aquellas oraciones que a su vez establezcan relaciones con otras subordinadas y cuyo manejo requiera de un mayor dominio sintáctico en el niño.

Ante los resultados de este análisis, la única conclusión relevante a la que se puede llegar es la de la necesidad de investigar la comprensión de las estructuras relativas en el niño, para tener la otra dimensión de su competencia sintáctica y poder así determinar las características de un momento dado de adquisición:

Sentences the child understands describe the scope of his grammar more accurately than those he produces[...] there is some evidence to suggest that the child comprehends sentences according to his existing grammar ${ }^{55}$.

Sólo así, sabiendo qué es lo que realmente comprende un niño de lo que produce, se podrá entender el porqué de sus muchas dificultades en el manejo de su lengua.

\section{Rebeca Barriga Villanueva}

El Colegio de México

caso aún en su producción, resultó ser también escaso en el adulto. Tal es el caso de la posición de OI. Esto habla, pues, no de un hecho de complejidad sino de frecuencia en el español.

${ }^{55}$ E. Klima y U. Bellugr, "Syntactic regularities in the speech of children", en Studies of child language development, p. 335. 


\section{APÉNDICE}

Oraciones Relativas dentro del Estudio Sociolingǘístico DEL LENGUAJE INFANTIL (1976).

EXPERIMENTO: "PlÁTICA LIBRE"

GRUPO OBRERO

1. Araceli Alvarado Espinoza $(7,0)$

1. *Mire, primero empezó de Pedro Infante y la muchacha que le decía la chorreada.

$\mathrm{OI}+$ caso

2. Ella jue la que se salvó.

3. Uno era su papá, era, cómo se llama, un señor que quién sabe cómo se llama.

4. *Y entonces el que quería más era a esta Chachita era a Pedro Infante.

OD

5. Era de Pedro Infante, de la muchacha qúu le decía chorreada.

$\mathrm{OI}+$ caso

6. *Era de un señor que se llamaba...

7. que le decían jorobadito.

$\mathrm{SU}$

8. El niño estaba ciego, dice una amiga mía que vive por mi casa.

9. Ya no me ha explicado las otras películas que ve. OD

10. A mi mamá le regalé lo que nos dieron en la escuela.

11. El día que le dieron el regalo, yo no fui.

12.Y si hay otro que no viene para acá me paso.

13. Unos amigos que tengo ahí en la escuela me llevan a ver una película.

14. Ellos son los que pagan los pasajes.

15. *Allá me voy a meter en la escuela que va ir.

16. * Le iba a decir a la muchacha que está acá con el otro niño, l'iba a decir que cómo se llama...

17. Cuando jui por la paleta que hice allá, en la esa

18. donde está la casita.

OD

19. Un día que tenga dos paletas, pero le digo que se puede hacer con una paleta, pero así chiquita. 
20. *El que, el que cómo se llama, el viejo de las tortillas, bueno, un día se pelió con una señora.

21. Es que un día que no fui,

SU

22. que se me olvidó traerlas ya no quiso.

23. Una niña que ensaya en la escuela también tiene los ojos verdes.

24. Hay unas dotoras que meten las abujas hasta adentro y

25. hay unas que nomás las meten hasta aquí. SU

26. Sí, pero los que vacunan.

27. El que le digo que es marica también está re flaco.

28. Le digo no, son las calcetas que están [este] así. SU

29. Y a la más chiquita que está flaquita como yo le dicen lombriz.

\section{Araceli Cornejo Torres $(6,7)$}

1. Los monos, esos que están en la pared.

\section{Alfredo Torres Peres $(6,4)$}

1. ${ }^{*}$ Del ataque de los pájaros que les atacan a los, a la gente.

2. Ahí venden mamilas, paletas y helados y chilitos que están en una bolsita.

3. Hasta la hermana tiene puercos y un perro que se llama oso.

4. Hay jardineros que riegan el pasto.

5. y a los que juegan, los mandan a la cárcel.

6. Animales y una rata que subió por la escalera y se comió esta carne.

\section{Garlos García Méndez (6.8)}

1. * Me gusta jugar a los policías, a los bomberos con la pileta y la ésa onde echa el agua.

2. Es que no sé hacer lo que hace él.

3. Es que no sé eso, lo que hace papá. 
5. José Antonio Castillo Lozano $(7,1)$

1. Tiene un jugador que está chutando la pelota. SU

\section{José Antonio García Escobar}

1. En la casa, lo que me diga mi papá lo hago. OD

2. Nosotros en mi casa, yo y una que se llama Blanca, mi hermana, jugamos a la escuelita.

3. Lo hacen, todo lo que yo les hice.

4. *En una casita donde encierran los conejos, pero ya los mataron.

5. *Toda la que no les conté.

OD

6. Una policía que tenga cuerda chiquita,

7. dos policías que se mueven.

7. José Manuel Córdoba López $(6,10)$

1. Un pato que se llama Pato Donal

2. que habla como pato

3. que tiene muchos amigos

4. *[este] Miki Maus, Tribilín, un perro que investigan.

5. Primero va cantando y cuando ve una cosa que está parada se esconde y le dispara.

6. Que no tiene techo, así.

7. *A una parte que esté bonito.

8. *E1 más chico agarraba cosas de que eran de vidrio.

9. Un niño se encontró un juguetito que caminaba y tenía cuerda.

OD, OD

10. Tenían muchos hijos que se parecían a Pinocho.

11. Luego los dos compraron esas tiras, esas que les dicen tripas.

12. *Era el más chico el que iba, él iba, ya iba al kinder.

8. Jorge Martín Lina Huicochea $(6,11)$

1. Nos queríamos meter para agarrar el dinero que tenían. 
2. *Fuimos a ver el pozo que se cayó una cubeta y la agarraba.

3. Porque se mueren los niños que apenas van a nacer.

\section{Lorena Gutiérrez Serna $(6,5)$}

1. Y le regalaba a los niños una muñequita qae ya esté grande

2. o una muñeca que tenga carreola.

3. Nada más tantitas cosas porque si les da muchas los primos que son muy malos les toca todo.

4. *Si rompen un vidrio que ya esté muy grande, grande el niño.

10. León LóPez Rivas $(6,8)$

1. Y se volteó el coche a la hora que lo voltiaron se quemó.

2. Y los llevaron al hospital y a la hora que los llevaron el doctor dijo ya no se les puede hacer nada.

3. Algunos niños se cain y hay veces que se cain y se revuelcan.

4. ${ }^{*}$ Hay veces que llevan niños resorteras y piedras.

5. Una vez que echaron una piedra le cayó a un niño.

$\mathrm{CC}$

6. Un niño bien grosero que siempre trai la resortera y él es el culpable de todo.

7. Es lo único que pienso.

OD

11. Lidia Martínez Hernández $(6,8)$

1. Mi hermana Malena la que viene a la escuela.

2. Uno que es puro cuadro.

3. Con un señor que se llama Chepo.

12. Lorena Miznáhuatl Hernández $(6,11)$

1. Me asusté una vez que me subí

2. en una bicicleta que tengo. 
3. Ayer le regalé a mi mamá un plato de esos que se cuelgan.

4. * Mi hermano el otro, le regaló uno de esos que echan un vaso así.

5. * Mi hermano le regaló unas que se echan tijeras, abujas.

$\mathrm{CC}$

6. El otro señor que le dicen Juanito va allá.

OI +caso

7. *Entonces un hermano, como es, que se llama Jaime y mi otro hermano Javier estuvo regando.

8. El chavo el que le pega atrás dice que yo soy.

9. Eso es una iglesia que está pintada.

10. Y las otras, esas que están allí sentadas, las senoritas.

11. La otra que una vez les enseñó a las niñas a hacer un muñeca.

12. Hizo bolitas, palos de éstos que se hacen así.

13. El queso es de rancho, el que tiene sal es de rancho.

14. Éste es un niño que se llama Miguel

15. que también va con nosotros.

\section{María del Carmen Ríos Gómez $(6,9)$}

1. A mí no me pega nomás a los niños que hacen lata

2. como a un niño que se llama Martín.

3. *Andan con ellos con los niños que se llaman Martín.

4. Ahí se meten y meten a las niñas que encantan.

14. Martha Esperanza Gruz Mancinas $(6,6)$

1. Ya nomás me alcanza para una plana que puso la maestra.

2. La otra véz qù estaba el niño sentado CC

3. y que estaba yo allá, le estaba poniendo la grabadora el otro señor.

4. Otro niño que vive allí, dijo que no estaban. SU

5. El morral se lo dejé encargado con la otra que se sienta atrás. 
6. La señora esa que nos dio el mole, nos trajo en la noche.

15. Marcos Gerardo Rodríguez López $(6,6)$

1. Ora que es lunes, es que a mi papá le gusta ver películas en inglés.

$\mathrm{CC}$

16. Patricia García Venegas $(6,7)$

1. Quién sabe cómo se llamaba lo que traía todo aquí.

2. Y bien haltos regalos que tenía.

3. Márgara y mi prima Juana que va en sexto se estaban agarre y agarre.

4. Jugamos con ung niña que sí nos conoce,

5. que se llama Lola.

6. y luego una primita que yo también tengo

OD

7. que es de mi otra tía una güera, le dice cómo hacen los soldados.

8. Un día mi primo Arturo que es bien chistoso lo llevó.

9. El que estaba allí sentado.

10. que estaba llorando.

11. Tenían un lorito que les había regalado Caperucita.

12. Ahí se queda Caperucita y un hada madrina que siempre se le aparecía a Caperucita, la hada madrina.

13. El pecoso y el otro señor que no querían al lobo $\mathrm{y}$ al zorrillito, luego se van a quedar veinte días en la cárcel.

14. Bueno sí se murió, pero era otro lorito qúe le pasaron por ahí.

17. Rafael Álamos Mendoza $(6,8)$

1. ${ }^{*}$ Tengo a Enrique, son dos Enriques en mi salón, Juan Manuel, Juan Antonio, Carlos y un niño que se llama Miguel, Isidro, Hilario, Óscar, Marco Antonio.

2. *Le faltaba uno abrir el que no le dijo que no lo abriera. 
3. *Llegó Barba Azul y le hace, dame las llaves, y le dio, la dio, nomás le dio las que, las otras.

4. ${ }^{*}$ Un señor, un señor que cada día [este, este] en sí los días va por mi casa, y ahí antes va descalzo.

18. Rebeca Huerta Cañada $(6,8)$

1. Y yo me iba a pasar para la cama chica la que está en nuestra cama.

2. El lunes cuando llegó mi mamá, barrimos.

CC

3. *Mira que feo esa máscara que está en el árbol.

4. *Es su pelo o es la flor, la que se está tapada la cabeza.

5. Tomó el camión y dice en el camión la casa donde vive la abuelita.

6. Y encuentra el lobo que está que está pegado.

7. Côn la cubeta que le echó el gato el agua al lobo, que el lobo se enoja y le pega con la cubeta al gato.

OBL + caso

8. Le dio dos flechas una para matar a la sombra que se le estaba aproximando.

9. La que es mujer se va con niña mujer

10. *la que es hombre se va con niño hombre.

19. Sergio Juárez Ávila $(6,11)$

1. ${ }^{*} \mathrm{La}$, el que se saque un diez va a mi casa.

2. *También hay una que está que está,

3. que tiene que subir escaleras.

4. *También le llama a los que no viven ahí. SU

5. Uno que va en tercero.

20. Zita Torres Villegas $(6,10)$

1. Y el que se esconde, ése le toca.

2. Una muñeca que se llama enfermera, cura bien a los enfermos.

3. Hay unos niños que se suben a su cunita solos. SU

4. Una tina donde brincan los niños y $\mathrm{CC}$

5. donde se sienta la niñita. 
6. Es una niña que se llama Martita.

7. * La silla donde se sientan las niñas, la mamá les habla para comer.

CC

\section{GRUPO MARGINAL}

21. Agustina Esquivel Vargas $(6,6)$

1. *Yo le dije al Santos Reyes que me trajeran una muñeca que hacía caritas.

2. Mi mamá me trajo una muñeca del kinder donde va mi hermano.

$\mathrm{CC}$

3. *Se le rompió la, con lo que maneja.

$\mathrm{OBL}+$ caso

4. *Mi hermano tenía un, [este], un d'sos con lo qué sube un pie.

OBL + caso

\section{Gatalina Tapia Orduña}

Fuera de la muestra porque no quiso hablar.

23. David Barajas Jaimes $(6,4)$

1. La que trabajó conmigo en el salón de mi hermana.

2. Juego así, de coches que me dieron aquí, un coche.

OD

3. *Tengo una silla así como están ésas, que ésa era uno túneles, unos juentes que les pasa y salta.

4. Lo vi un día que yo estaba malo.

CC

24. Eloísa Sánchez Victoria $(6,10)$

1. Anduve corriendo con unos amigos que tengo.

OD

2. Otros niños que no conozco.

OD

25. Francisca Maldonado Tirado $(6,3)$

1. Y el que le toque dieciocho ése las trai. OI + caso 
2. Lo avientan y el que le toque dieciocho ése va y cuenta veinte.

3. Y el que se pare ya las trae.

$\mathrm{OI}+$ caso

$\mathrm{SU}$

SU

$\mathrm{SU}$

$\mathrm{OBL}+$ caso

$\mathrm{OBL}+$ caso

$\mathrm{CC}+$ caso

\section{Guillermina Domínguez Hernández $(7,0)$}

1. Mi mamá come junto con una señora que vive en mi casa

2. que se llama Lucila.

3. También una niña que se llama gorda.

4. También una niña que se llama Reyna.

5. *La niña grande que está cuidando a su hermanita se andaba llorando por su mamá.

28. Genaro Ramírez Hernández $(6,8)$

1. Nada más mis hermanas que van aquí en esta escuela.

2. No nada más una que va en el salón anaranjado.

29. Hortensia Pérez Hernández $(6,1)$

1. El que pierde ya le agarra.

2. Ya hicimos tarea de lo que pone en el pizarrón.

3. *Hacemos tarea la que les dice la maestra.

30. Jorge Mejía Reséndiz $(6,8)$

1. Nada más todo eso fue lo que pasó.

2. *Eso es de lo que no he visto. 
3. *Todo lo que se había quemado, un coche de carga se lo llevaron.

31. José Roberto Martínez González

Fuera de la muestra porque no quiso hablar.

32. Luciano Arcos García $(7,1)$

1. Era mi amigo que se nombraba Raúl.

33. Laura Osorio Carmona $(6,0)$

1. De lo de un señor que se cayó en la cantera.

2. La Cruz Roja, la que se llevó al viejito ése, se llevó al señor.

3. Porque iba a ver a [este] a ver a una señora que se murió.

4. una señora que se llama Jesú.

34. Miriam Elizabeth Vargas Salas $(6,11)$

No produjo relativas.

35. Mercedes Margarita Paredes Camacho $(6,10)$

1. El que hice el otro día.

OD

36. Ricardo Parra Paredes $(6,9)$

1. Un amigo que no quiere que juege canicas. SU

2. El que, el que manda. SU

3. Pues el que no juega. SU

4. El que no juega, ese señor SU

5. Pues el que anda dentro de portero, nos dio. SU

6. Un amigo que hace una escuela y le pintó los salones de rojo. SU

7. Vi una chamaca que me pega. OD

8. Y después un amigo que se sube en una bicicleta y se cayó. $\quad \mathrm{SU}$

9. Uno que le chinta el pastel y se enojó mi papá. SU 
10. Los pasteles que no sean de la luna saben feos. SU

11. Un niño que se cai desde segundo allí, $\quad \mathrm{SU}$

12. que se cai allí, de allí.

13. A un amigo qué le estábamos brincando se cayó.

$\mathrm{OI}+$ caso

14. Es eso, es todo lo que soñé.

OD

37. Sixto Álvarez Díaz $(6,7)$

1. Y el que, y si uno lo pasa y lo toca ya está encantado.

2. *Unó que se llamaba,

3. que era mi tío vio una bruja.

38. Silvestre Toribio Martínez $(6,8)$

1. Y hay un niño que se llama Maximino y trai bien harto dinero.

2. Un día que salíamos de la escuela sacó un billete de a cinco.

3. Un día que me iba a acostar con mi hermana

4. la que me pegó, me iba a'orcar

5. *Es que mi amigo Daniel el que le dije que andábamos por aquí y que me pisa.

6. *Tiene un osó que se,

7. tiene un perro que se llama oso.

8. *Le ladran a los señores que pasan.

9. Es que mi hermano grande que tiene diez años,

10. iba a comprar con una señora que tiene dos perros.

11. Nos dijo que nos lleváramos al perro que me mordió.

12. Tenemos un perrito chiquito que se llama Camitán

13. que cuando maneció que ya no estaba.

14. El primer día que lo trajo mi papá le dimos sopa.

15. Un día que le habían dado trabajo a mi papá ya se había enfermado.

16. Trabaja con un señor que se llama Camacho. 
17. También un amigo mío que se llama Chago y su papá se lo llevó a trabajar.

39. Teresa lópez Matías $(6,4)$

1. Es una que se llama Nacha y SU

2. otra que se llama Mosco. SU

3. Es un señor que tiene barbas poquitas. SU

40. Verónica Gampos Servín $(6,7)$

1. Una amiga que tengo, saca unos juguetitos. OD

2. Sacamos una muñeca que tenemos de mi hermana, OD

3. que nos trajeron los Santos Reyes. OD

4. Y mi amiga Lucero, una amiga que se llama Lucero saca juguetitos.

5. Y una amiga que tiene

6. que se llama Licha saca con su ese de calentar.

7. Contamos y al que le toque dieciocho, ése se sale.

8. *Y la niña que se salió, le dijo ¡tramposos! nos dijo a nosotros.

9. Voy con mi hermana con una señora que tiene columpios.

10. Nomás los dulces que me trai mi hermana Carmen.

OD

11. Y yo voy a comprarlos con el dinero que me da mi hermana Rosa.

OD

12. Le damos el desperdicio que desperdiciamos nosotros.

OD

\section{GRUPO MEDIO}

\section{Ana Luz Segura Monroy $(6,7)$}

1. Uno que me enseñó la maestra de aquí.

2. Una niña güera que cs su cumpleaños y que no sé cuántos cumple. 
3. Un perrito que se llama, no sé cómo se llama. SU

4. ${ }^{*}$ Los dejaron recortar palabras que vayan con, cómo se llama, con d'sa, cómo es, cómo se llama la letra.

5. Y mi abuelito fue el que trajo el tocacintas para acá.

6. *Tamén tengo uno que se le jala.

7. una que se llama Bárbara.

8. que se le jala aquí y dice cosas.

SU

OI + caso

$\mathrm{SU}$

$\mathrm{OI}+$ caso

42. Adrián Pontón Pérez $(6,8)$

1. Y el que vaya anotando un gol ése se va poniendo.

2. Y también jugamos a agarrar a otro, a lo que le dijimos

3. *el otro día cuando vino Álvaro y yo.

OD

4. El que agarre a uno tiene que agarrar

$\mathrm{CC}$

5. al que agarró al otro.

$\mathrm{SU}$

6. Con los que juego son Salvador, Adolfo, Manuel, Pedrito y también Álvaro.

SU

7. El que diga mano, se tiene que ir a la bas.

$\mathrm{OBL}+$ caso

8. Al que le toca dieciocho, ése las trai.

$\mathrm{SU}$

9. Y el quien lo agarre, ése está encantado.

$\mathrm{OI}+$ caso

10. El primero que lo agarra ése las trai.

$\mathrm{SU}$

$\mathrm{SU}$

43. Claudia Estela Gasillas $(6,9)$

1. Otra vez se durmió hasta en la tardecita que ya estaba haciendo mi tarea.

CC

44. Cllaudia G. IzQuierdo $(6,7)$

1. Y mi agüelito como está viejito lo que no sabe es quién hizo el barro.

2. Yo no la cojo, la cogen otros hombres que ellas saben.

3. *Pero el que lo había robado, era a nosotros el de junto.

45. Claudia Odette Terrero $(6,7)$

1. El que lo atrapa es el lobo. 
46. David Humberto Rojas Nieto $(6,8)$

1. Un día había unos pintores que estaban pintando la casa.

2. Gana un equipo que se llama rojo.

3. El equipo que tiene la camiseta roja y se llama Tepichín.

4. Sobre un incendio en una fábrica que vi.

5. Se me va a caer esta uña porque aquí se ve el hoyo que se va cayendo.

\section{7. Édgar Mendoza Chávez $(6,6)$}

1. Mañana voy a ir con un amigo que se llama Jaime.

2. Tengo uno también de carreras que tiene un muñequito.

3. *nada más que como ése tiene algo donde lo tocas se calienta.

$\mathrm{CC}$

4. Son las llantas de atrás las que empujan a las de adelante.

5. Tengo una hermana que también sabe eso.

$\mathrm{SU}$

6. Nomás que no tenemos una cosa con que se solda el coche.

OBL + caso

7. Y juego con mi Supermán que me regaló.

OD

8. Un señor que es buceador vio muchos tiburones.

9. Vi a un niño que estaba dormido en el agua.

10. * Le quiero poner unos tanques a mis muñecos así, con aire y apretarle así, con hilo que se metan así prrr prrr prrr con un caballo.

11. Desde que he visto mucho a Ramón Bravo que pasa mucho en la matiné.

12. Taba pensando que por qué no me metía abajo y subía, lo que estaba pensando en la alberca.

13. Y sale una planta d'sas que tienen unos picos.

14. *Le digo a mi papá que me compre unos de esos pescaditos que van

15. que están en el Superama 
16. que no están en venta pero a ver a cuánto nos dejan.

48. Erika Sofía Arteaga Humara $(6,5)$

1. La que me deja la maestra.

2. Nos vamos a calificar lo que los pone la maestra.

3. El que sale en el Chavo.

49. Eduardo Valdés García $(6,9)$

1. No me gusta que me digan lo que tengo que hacer.

50. Gerardo de la Huerta lópez $(6,5)$

1. Yo era el que me cortaba más.

2. Al otro día le veo la mano donde se cortó,

CC

3. un día, el día que fuimos a Toluca.

$\mathrm{CC}$

4. Había un camión que se le había caído una ruedita así

$\mathrm{OI}+$ caso

5. que era por donde se abría la puerta.

$\mathrm{SU}$

6. Y también un día que invitaron a mi hermana a una fiesta.

CC

7. Y lo que le preocupa más a mi mamá es que se llevó sus llaves.

8. Pero a ella lo que le preocupa son sus llaves.

51. Grisel Sandra Aguilar Rincón $(7,1)$

1. Mi hermâna Fabiola que es más grande que ya tiene once años.

2. Como mi hermanito Ulises que va en el kinder, tiene un carro chico.

3. Se brincó la bardita que le hicimos.

OD

4. Hugo que el es

$\mathrm{SU}+$ caso

5. el que lo trajo.

$\mathrm{SU}$

6. Se fue a un parque que está cerca de nuestra casa.

7. Teníamos un perro más grande que se nos murió. 
8. Le pegó una enfermedad que ese perro tenía. OD

9. Lo enterramos en una tienda que tenemos así. OD

10. Yo y mi hermanito que va en el kinder salimos en la tarde y le pusimos muchas florecitas.

11. *Porque no tiene llave, la que tiene es mi papá y mi hermana.

52. José Álvaro Elizalde Rojas $(6,11)$

1. Tienen que escoger a un portero, a los amigos que quieran.

2. Los que corren más veloces son los de nuestro equipo.

3. Y los que no corren mucho no son de nuestro equipo.

4. Un día perdimos porque escogimos a un niño que no corría.

5. Lo que los deja la maestra para trabajar.

6. Las palabras que no hemos aprendido.

OD

7. Un día que nos dejan de vacaciones nosotros juimos, mi papá y yo nos juimos a Acapulco.

8. Porque tenemos una Catalina que tiene allí resbaladillas.

9. ${ }^{*}$ Tenemos un platillo volador que parecen tazas.

10. *Hay una escaleras que se suben y ya se pueden meter.

11. Los dio cada vez nostra maestra juguetes a los que se portaban más bien.

12. Y los regaló juguetes, todos los juguetes que había en el salón.

13. * Los que quieran jugar al hombre nuclear, todos tienen

14. los que quieran jugar al nombre nuclear tienen que decirnos si quieren jugar o no.

15. Ponemos un muñeco de plástico y a mí que soy el hombre nuclear.

16. Aquí trabaja una maestra que es amiga de mi mamá.

17. Primero alguien que tiene traje de Batman y una máscara y su traje se pone como Batman. 
53. Jorge Edmundo García Gutiérrez $(6,2)$

1. ${ }^{*} \mathrm{Y}$ ya le sacan todo lo que tienen de mugre. $\mathrm{OD}$

2. * Cuando que les sirven así con algo que tienen nueces, se le mueve algo.

3. *A mis hermanos no les espanta pero, con lo que ya, ya les van a componer las muelas y ya se las quitan con eso

OBL + caso

54. Juan Javier Sánchez Fragoso $(7,0)$

1. *El un, el primero que sacó las trai después se echa a correr.

55. Jorge ZúNiga Carrasco $(6,10)$

1. Había una vez abejita, la que nos dijo la maestra,

2. que estaba muy pero muy aburrida.

3. Hay una pastelería con muchos pasteles sabrosos que sé que a ti te van a gustar.

4. En verdad, el que me gustó más fue SU

5. el que iba haciendo tic tac.

$\mathrm{SU}$

6. En primer lugar, lo que yo hago llegando a mi casa es mi tarea.

OD

56. Luis Alfonso anaya Coutiño $(6,10)$

1. Porque un día que vine a cambiar al salón, me las quitaron.

CC

57. Leticia Manterola Nieto $(6,9)$

1. Hicimos un regalo y unos dulces compramos, eso es lo que le hicimos.

2. Es mexicana la película, es la única que es. SU

3. Una que se llama Claudia, SU

4. la que tiene el chal, Claudia Castilla y SU

5. una amiga que se llama María Elena. SU

58. María de los Ángeles Leglesse Cisneros $(7,1)$

1. Hice mi tarea que me dejaron, después me fui. OD 
2. Se las habían dado a los señores que piden tortillas duras.

3. Él tiene un triciclo que le presta a mi hermanito el más chiquito.

4. *Unas veces me invitan a la casa de una amiga que me invita mi amiga.

5. Nos vamos a jugar con las muñecas que tiene allí.

OD

6. $\mathrm{Y}$ ahí tiene una muñequita que no puede sacar porque está bien bonita.

7. Se le rompen con sus hermanos que son bien rompelones.

8. Juntos vamos a jugar a un parquecito que tiene allí abajo.

9. Y ahí no dejan salir a un hermanito que es más rompelón que todos.

10. Y luego pieza a salir y pieza a romper sus juguetes que tienen allí abajo.

11. Y al otro día que vienen nos vamos en bicicleta.

12. *Aquí hay una tiendita donde siempre mi má, siempre ven mis hermanitos la tiendita.

$\mathrm{CC}$

59. Miguel Ángel Ledezma Estrada $(6,10)$

1. Y el que lo agarre, lo agarró.

2. Anotan goles y el que gane pus ya ganó.

3. Estaban volando unos aviones así, de los que les inventan.

4. Para los deportistas que vienen

5. los que juegan

6.los que vienen

7. los que también como nosotros se ponen a manejar.

8. Pus de lo que sea.

9. Era que le demos vuelta al d'se el que lleva,

10. que se hace así.

11. Un volkswagen que tiene casi como dos días y no se nos ha descompuesto.

12. Después se habían ido a remar con las esas, con los barcos, con esas lanchitas que se cayeron. 
13. El otro día que fuimos a la fábrica de lápices nos fuimos y nos regalaron lápices.

14. A un chamaquito que nosotros vimos, un caballo estaba suelto y que le hace así.

\section{Verónica María Inés Huerta Ramírez}

No produjo relativas.

61. Edgardo Quintero Ibañez $(7,0)$

1. Fui a hablarle a un miño que no es de esta escuela

2. que es de la Bravo

3. que se llama Joel.

4. Y mi hermanita se subió a la azotea donde está mi perro.

5. * Le voy a pedir una que, una de esas que tienen el palo aquí.

6. Él tiene una cosa que se puede hacer. 